\title{
MiR-10b Directly Targets ZEB1 and PIK3CA to Curb Adenomyotic Epithelial Cell Invasiveness via Upregulation of E-Cadherin and Inhibition of Akt Phosphorylation
}

\author{
Ying Guo ${ }^{a}$ Xiao Lang ${ }^{b}$ Zhen Lu Jianchao Wang ${ }^{a}$ Ting Lia ${ }^{a}$ Ying Liao ${ }^{a}$ \\ Chunyan Jiac ${ }^{c}$ Wenxia Zhao ${ }^{d}$ Huiqi Fang ${ }^{a}$
}

aDepartment of Gynaecology, Shanghai Municipal Hospital of Traditional Chinese Medicine affiliated to Shanghai TCM University, Shanghai, ${ }^{b}$ Department of Gynaecology and Obstetrics, International Peace Maternal and Child Health Hospital affiliated to Shanghai Jiao Tong University, Shanghai, 'Department of Ultrasonograpy, Shanghai Municipal Hospital of Traditional Chinese Medicine affiliated to Shanghai TCM University, Shanghai, 'Department of Gynaecology and Obstetrics, Shanghai Jiang Wan Hospital, Shanghai, China

\section{Key Words}

MiR-10b • Adenomyosis • E-cadherin • Akt

\begin{abstract}
Background/Aims: Adenomyosis is a disease in which ectopic endometrial glands and stromal cells appear in the uterine myometrium. Despite its prevalence, the molecular mechanisms involved in the development of adenomyosis are largely unknown. The aim of this study was to investigate the role of miR-10b and its target genes ZEB1 and PIK3CA in adenomyosis. Methods: 1387 miRNAs in human normal endometrium and ectopic endometrial lesions of adenomyosis using a microarray screen assay. The significant differential expression of 10 miRNAs was confirmed by qRT-PCR. The expression of miR-10b in endometrial epithelial cells isolated from normal endometrium and paired eutopic and ectopic endometrium of adenomyosis was measured by qRT-PCR. Subsequently, the targets of miR-10b were predicted by bioinformatics and confirmed using a luciferase assay, and the mRNA and protein expression of ZEB1 and PIK3CA were assessed in the endometrium or endometrial epithelial cells by qRT-PCR and western blotting or immunohistochemical analysis. Cell migration and cell invasion of endometrial epithelial cells with different treatments by Transwell assays. The expression of $\mathrm{p}-\mathrm{AKT}$, Akt and E-cadherin proteins was determined by Western blot analysis. Results: MiR-10b expression was significantly downregulated in both adenomyotic lesions and adenomyotic epithelial cells. MiR-10b overexpression in adenomyotic epithelial cells inhibited cell migration and invasion. We then demonstrated that miR-10b directly targets the $3^{\prime}$-UTRs Y. Guo and X. Lang contribute equally to this work.

Ying Liao, Prof., MD

Department of Gynaecology, Shanghai Municipal Hospital of Traditional Chinese Medicine affiliated to Shanghai TCM University, No 274, Middle Zhijiang Road, Zhabei District, Shanghai 200071 (China)

Tel. +86-021-56639828, Fax 86-021-56639486, E-Mail yingdoctor@126.com
\end{abstract}

KARGER 125 


\section{Cellular Physiology Cell Physiol Biochem 2015;35:2169-2180

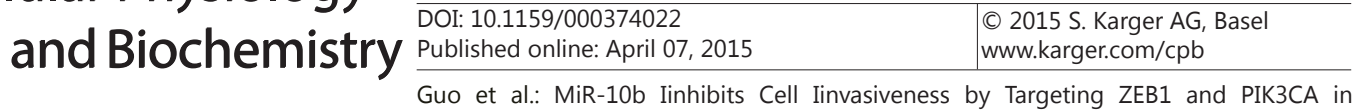 Adenomyosis}

of ZEB1 and PIK3CA, and downregulates ZEB1 and PIK3CA in adenomyotic epithelial cells, leading to increased $\mathrm{E}$-cadherin expression and decreased Akt phosphorylation. Conclusions: miR-10b directly targets ZEB1 and PIK3CA to curb adenomyotic epithelial cell invasiveness via upregulation of E-Cadherin and inhibition of Akt phosphorylation.

Copyright $\odot 2015$ S. Karger AG, Basel

\section{Introduction}

Adenomyosis is a common, benign, gynecological disorder characterized by the invasion of endometrial epithelial cells into the myometrium of uterus. Adenomyosis can cause menorrhagia, dysmenorrhea, chronic pelvic pain, and preterm labor in women of reproductive age, and is associated with an increased risk of anemia [1,2]. Substantial evidence indicates that adenomyosis is prompted and driven by the effects of estrogen [3]. Oestrogen-enhanced migratory and invasive properties of endometrial epithelial cells underlie the ability of the endometrium to infiltrate the myometrial junctional zone and the growth of ectopic tissue $[3,4]$. However, the specific signaling pathways involved in the regulation of the motility and invasiveness of endometrial epithelial cells are not well understood.

MicroRNAs (miRNAs) are single-stranded noncoding RNAs of about 22 nucleotides that suppress the expression of target genes to regulate diverse cellular processes. Many miRNAs are implicated in tumor growth and metastasis [5]. Of these miRNAs, miR-10b is upregulated in a number of human cancers, promoting cancer cell migration and invasion [6-10]. However, miR-10b is found to be downregulated in endometrial cancers such as endometrial serous adenocarcinoma (ESA) and endometrioid endometrial carcinoma [11, 12]. In particular, the lower expression of miR-10b is significantly correlated with poor overall survival in ESA [11]. These data suggest that, opposite of its oncogenic activity in other cancer types, miR-10b acts as a tumor suppressor in cancers of endometrium origin. MiR-10b is also found to be downregulated in endometriotic tissues of women with endometriosis [13]. In vitro studies reveal that miR-10b directly targets syndecan- 1 to curb invasiveness of human endometriotic cells [14], suggesting that miR-10b plays an inhibitory role in the development of endometriosis. However, the expression and function of miR-10b in adenomyosis, a condition closely related to endometriosis, have not been reported.

Epithelial-mesenchymal transition (EMT) is characterized by loss of cell-to-cell adhesion and increased cell motility, and is closely associated with the invasion and metastasis of several cancers [15]. One of the hallmarks of EMT is the down-regulation of E-cadherin, which is repressed by several transcription factors including ZEB1, ZEB2, SNAI1, SNAI2, Twist1, Twist2 and E12/E47 [16]. Interestingly, several recent studies have shown that E-cadherin expression is downregulated in epithelial component of human adenomyotic lesions, suggesting that EMT plays a crucial role in the development of adenomyosis $[4,17]$. The PI3K/Akt survival pathway, which is activated by estrogen, is also implicated in the pathogenesis of adenomyosis $[18,19]$.

In the present work, we first compared the expression of miR-10b in human adenomyosis versus healthy controls. We subsequently investigated the function of miR-10b in the development of adenomyosis in the context of the migration and invasion of adenomyotic epithelial cells. Finally, we examined the regulatory relationship between miR-10b and putative target genes ZEB1 and PIK3CA and explored the involvement of E-cadherin and Akt, which act downstream of ZEB1 and PIK3CA in miR-10b-induced effects.

\section{Materials and Methods}

Patients and tissue collection

The study protocol was approved by the Ethics Review Board of JiangWan Hospital, Shanghai, China. The study was conducted in accordance with the Declaration of Helsinki and applicable regulations in China. All study participants gave written informed consent. 


\section{Cellular Physiology Cell Physiol Biochem 2015;35:2169-2180 \begin{tabular}{ll|l} 
and Biochemistry & $\begin{array}{l}\text { DOI: 10.1159/000374022 } \\
\text { Published online: April 07, 2015 }\end{array}$ & $\begin{array}{l}\text { ( ) 2015 S. Karger AG, Basel } \\
\text { www.karger.com/cpb }\end{array}$ \\
\cline { 2 - 3 }
\end{tabular} Guo et al.: MiR-10b Iinhibits Cell linvasiveness by Targeting ZEB1 and PIK3CA in Adenomyosis}

Paired eutopic and ectopic endometrial tissues were collected from premenopausal women with adenomyosis ( $\mathrm{n}=22,30$ - 39 years old) who underwent hysterectomy at JiangWan Hospital of Shanghai. These tissues were from different phases of the menstrual cycle. Normal endometrial tissues were collected from 13 premenopausal women without evidence of adenomyosis ( $n=13,29-41$ years old) who underwent hysterectomy for subserousal leiomyoma at the same hospital. Samples were immediately frozen and stored in liquid nitrogen until analysis.

\section{Microarray and analysis}

Fresh-frozen normal endometrial tissues and ectopic endometrial tissues of adenomyosis in TRIzol reagent were shipped to KangChen Bio-tech (Shanghai, China). MiRNAs were extracted, labeled, and hybridized to the Phalanx human miRNA OneArray (v5.1) containing probes for 1387 human miRNAs. Data were normalized using median normalization method. A heat map was created using Cluster 3.0 and JAVA Treeview software. All experiments and data analysis were carried out at KangChen Bio-tech.

\section{Quantitative real time PCR}

Total RNA was extracted from tissues and cells using Trizol reagent (Invitrogen, USA) according to the manufacturer's instructions. MiRNA cDNA was synthesized using a Mir-X miRNA First-Strand synthesis kit (Clontech, USA). Real-time quantitative PCR (qRT-PCR) was performed using a SYBR green qPCR kit (TaKaRa, Japan) on an Applied Biosystems 7300 QPCR System (Foster City, CA, USA). qRT-PCR was performed for 40 cycles (miRNAs: $95^{\circ} \mathrm{C}$ for $15 \mathrm{~s}$ and $60^{\circ} \mathrm{C}$ for $1 \mathrm{~min}$ after an initial $15 \mathrm{~min}$ incubation at $95^{\circ} \mathrm{C}$; $\mathrm{mRNAs}$ : $95^{\circ} \mathrm{C}$ for $10 \mathrm{~s}$ and $72^{\circ} \mathrm{C}$ for $30 \mathrm{~s}$ after an initial $3 \mathrm{~min}$ incubation at $95^{\circ} \mathrm{C}$ ). The data were analyzed according to the $2^{-\Delta \Delta C t}$ method [20], and the fold change in the expression of each miRNA or mRNA was normalized to RNU6B or GAPDH. Sequences of primers used in PCR are shown in Table 1.

Isolation and culture of human endometrial epithelial cells

Freshly collected normal endometrium and paired eutopic and ectopic endometrial tissues were processed and separated into stromal and epithelial cell fractions following previously described procedures [21]. The identity of the epithelial cell fraction was confirmed by morphological analysis and the expression of the glandular epithelial marker CD9 by immunofluorescence staining. Cells were cultured in DMEM/F12 supplemented with $10 \%$ fetal bovine serum (FBS) at $37^{\circ} \mathrm{C}, 5 \% \mathrm{CO}_{2}$ in a humidified incubator.

\section{RNA oligoribonucleotides and plasmids}

The shRNAs targeting human ZEB1 and PIK3CA transcripts were designated as shRNA-ZEB1 and shRNA-PIK3CA, respectively. The anti-miR-10b that had a sequence complementary to mature miR-10b was a 2'-O-methyl-modified oligoribonucleotide. The shRNAs and negative control shRNA-NC, anti-miR-10b and negative control anti-miR-NC, and miR-10b mimics (miR-10b) and negative control miR-NC mimics (miRNC) were synthesized at Genepharma (Shanghai, P. R. China). All negative control RNAs had sequences that were non-homologous to any human genome sequences.

Table 1. Sequences of primers used in qRT-PCR

\begin{tabular}{llll}
\hline & \multicolumn{1}{c}{ Forward } & \multicolumn{1}{c}{ Reverse } \\
\hline \multirow{5}{*}{ miR-10b } & 5'-CCAGAGGTTGTAACGTTGTCT-3' & 5'-TGCATCGACCATATATTCCCCT-3' \\
& miR-371b-5p & 5'-GGTAACACTCAAAAGATGGCGG-3' & 5'-GGCACTCAAACTGTGGGGG-3' \\
& miR-92b-5p & 5'-CTTTAAGCGGTGGGGAGCG-3' & 5'-TCCAGTCAATAGATCGGTCAGG-3' \\
& miR-30c & 5'-ACCATGCTGTAGTGTGTGTAAA-3' & 5'-AGTAAACAACCCTCTCCCAGC-3' \\
& miR-100 & 5'-AAACCAAGGGAAGCACGTTG-3' & 5'-GCATATAAGCAAAGCCCCAGG-3' \\
& miR-143 & 5'-CAGTGCTGCATCTCTGGTCA-3' & 5'-TGCAGAACAACTTCTCTCTTCCT-3' \\
& miR-532-3p & 5'-ACTTGCTTTCTCTCCTCCATGC-3' & 5'-CCTTGGGTGTGGGAGGGTAAT-3' \\
& miR-513a & 5'-CCACATTCAGCCATTCAGCG-3' & 5'-TGCAGTGCATGCTGTACATT-3' \\
& miR-466 & 5'-ATACACATAAGGTCCAGCAT-3' & 5'-GAGACCAGCAGGATGTGTG-3' \\
& miR-451a & 5'-GAAACCGTTACTTGCTATAC-3' & 5'-TTGCCATTCCAAGAACTCAGT-3' \\
& RNU6B & 5'-CTCGCTTCGGCAGCACA-3' & 5'-AACGCTTCACGAATTTGCGT-3' \\
& ZEB1 & 5'-GAGCAGCCTAGCCAACTTCA-3' & 5'-GGAGTGGAGGAGGCTGAGTA-3' \\
mRNA & PIK3CA & 5'-CCAGATCCTATGGTTCGAGGT-3' & 5'-CTCCAAAAGCAGGCCAAACC-3' \\
& GAPDH & 5'-GTCAAGGCTGAGACGGGAA-3' & 5'-ATGACGAACATGGGGGCATC-3' \\
\hline
\end{tabular}




\section{Cellular Physiology Cell Physiol Biochem 2015;35:2169-2180 \begin{tabular}{l|l} 
DOI: 10.1159/000374022 & $\begin{array}{l}\text { C 2015 S. Karger AG, Basel } \\
\text { www.karger.com/cpb }\end{array}$ \\
\hline
\end{tabular} Guo et al.: MiR-10b Iinhibits Cell linvasiveness by Targeting ZEB1 and PIK3CA in Adenomyosis}

The wild type 3'-UTRs of human ZEB1 and PIK3CA were amplified from human genomic DNA by PCR using the following primers: pGL3-ZEB1 forward, 5'-GGCGAGAGTAGTGAGCAAGT-3', reverse, 5'-ACCCTGTTAGGCAGTGAGGA-3'; pGL3-PIK3CA forward, 5' ${ }^{\prime}$-TCATGGTGGCTGGACAACAA-3', reverse, 5'-ACTTAAGGCATAACATGAAATTGCG-3'. Mutant 3'-UTRs of ZEB1 and PIK3CA containing mutations at the miR-10b binding site were created using the QuikChange site-directed mutagenesis kit from Stratagene (La Jolla, CA, USA) following manufacturer's instructions. The wild type and mutant 3 '-UTRs were introduced into the pGL3 luciferase reporter vector (Promega, USA) downstream of the luciferase gene.

\section{Cell transfections}

Endometrial epithelial cells isolated from ectopic endometrial tissues of adenomyosis patients were seeded in 12-well plates, cultured for $24 \mathrm{~h}$, and then transfected with RNA oligoribonucleotides or plasmids. All transfections were performed using Lipofectamine 2000 (Invitrogen, USA) according to the manufacturer's instructions. Cells were collected $48 \mathrm{~h}$ after transfection and used in subsequent studies.

\section{Cell migration and invasion assays}

Cell migration and Invasion assays were performed as previously described using uncoated and matrigel-coated Transwell systems, respectively ( 8 - $\mu \mathrm{m}$ pore size, polycarbonate membrane; BD Biosciences, USA) [22]. Briefly, $5 \times 10^{4}$ cells resuspended in $200 \mu \mathrm{l}$ serum-free DMEM/F12 medium were added to the upper inserts whilst the lower chamber was loaded with $500 \mu \mathrm{l}$ medium supplemented with $10 \%$ FBS, serving as a chemoattractant. After $24 \mathrm{~h}$ incubation at $37^{\circ} \mathrm{C}$, cells that had moved through the member and adhered to the lower surface of the membrane were counted under a microscope.

\section{Luciferase reporter assay}

Dual-Luciferase reporter assays (Promega, USA) were performed following manufacturer's instructions as previously described [23]. Briefly, HEK293T cells were seeded in 12-well plates and cultured in DMEM/ $\mathrm{F} 12$ at $37^{\circ} \mathrm{C}$ for $24 \mathrm{~h}$. Cells were subsequently co-transfected with $50 \mathrm{nM}$ of miR-10b or miR-NC and $100 \mathrm{ng}$ of firefly luciferase reporter plasmid comprising the wild-type or mutant 3'-UTR using Lipofectamine 2000 (Life Technologies, USA). Luciferase activity was detected $48 \mathrm{~h}$ after transfection and normalized to Renilla activity. Each experiment was conducted as duplicate and was repeated three times.

\section{Western blot analysis}

Whole cell lysates were obtained using the M-Per Mammalian Protein Extraction Reagent (Pierce Biotechnology, USA). Total proteins $(20 \mu \mathrm{g})$ were separated on $10 \%$ SDS-PAGE, transferred to nitrocellulose membranes, and probed with antibodies to ZEB1 (1:2000; Abcam, Cambridge, MA), PIK3CA (1:500; Santa Cruz Biotechnology, Santa Cruz, CA), Akt (1:10000; Abcam), phospho-Akt (Ser 473; 1:5000; Abcam), E-cadherin (1:500; Abcam), and $\beta$-actin (1:2000; Abcam), respectively. After extensive washing, membranes were incubated for $1 \mathrm{~h}$ at room temperature with goat polyclonal anti-rabbit IgG-H\&L-pre-adsorbed (HRP) at 1:2000 dilution (Abcam). Bands were detected using the enhanced chemiluminescence (ECL) blotting analysis system (Amersham Pharmacia Biotech, UK). The densitometric values were determined using a gel image analysis system (Bio-Rad, Hercules, CA) normalized to $\beta$-actin.

\section{Immunohistochemical analysis}

Formalin-fixed, paraffin-embedded blocks of normal endometrium and paired eutopic and ectopic endometrial tissues of adenomyosis were subjected to immunohistochemical analysis for the expression of ZEB1 and PIK3CA. The streptavidin-biotin peroxidase complex technique was used for staining as previously described [24]. The formalin-fixed, paraffin-embedded sections were stained with rabbit monoclonal antibody to ZEB1 (1:100; Abcam) or PIK3CA (1:200; Santa Cruz Biotechnology). The degree of the sections was evaluated independently by two observers using light microscopy (Olympus BX-50; Olympus Optical, Tokyo, Japan) (10 fields per section, 200x). Sections were scored according to the percentage of stained cells: $<1 \%$, negative $(-) ; 1-5 \%$, borderline $( \pm) ; 5-25 \%$, intermediate $(+) ; 25-50 \%$, moderate $(++) ; 50-75 \%$, strong $(+++) ; 75-100 \%$, very strong $(++++)$. Cells were then classified as either negatively stained $(-/ \pm)$ or positively stained $(+/++/+++/++++)$.

\section{KARGER}




\section{Cellular Physiology Cell Physiol Biochem 2015;35:2169-2180 \begin{tabular}{l|l} 
DOI: 10.1159/000374022 & $\begin{array}{l}\text { O 2015 S. Karger AG, Basel } \\
\text { www.karger.com/cpb }\end{array}$ \\
\hline
\end{tabular} \\ Guo et al:: MiR-10b Iinhibits Cell Iinvasiveness by Targeting ZEB1 and PIK3CA in Adenomyosis}

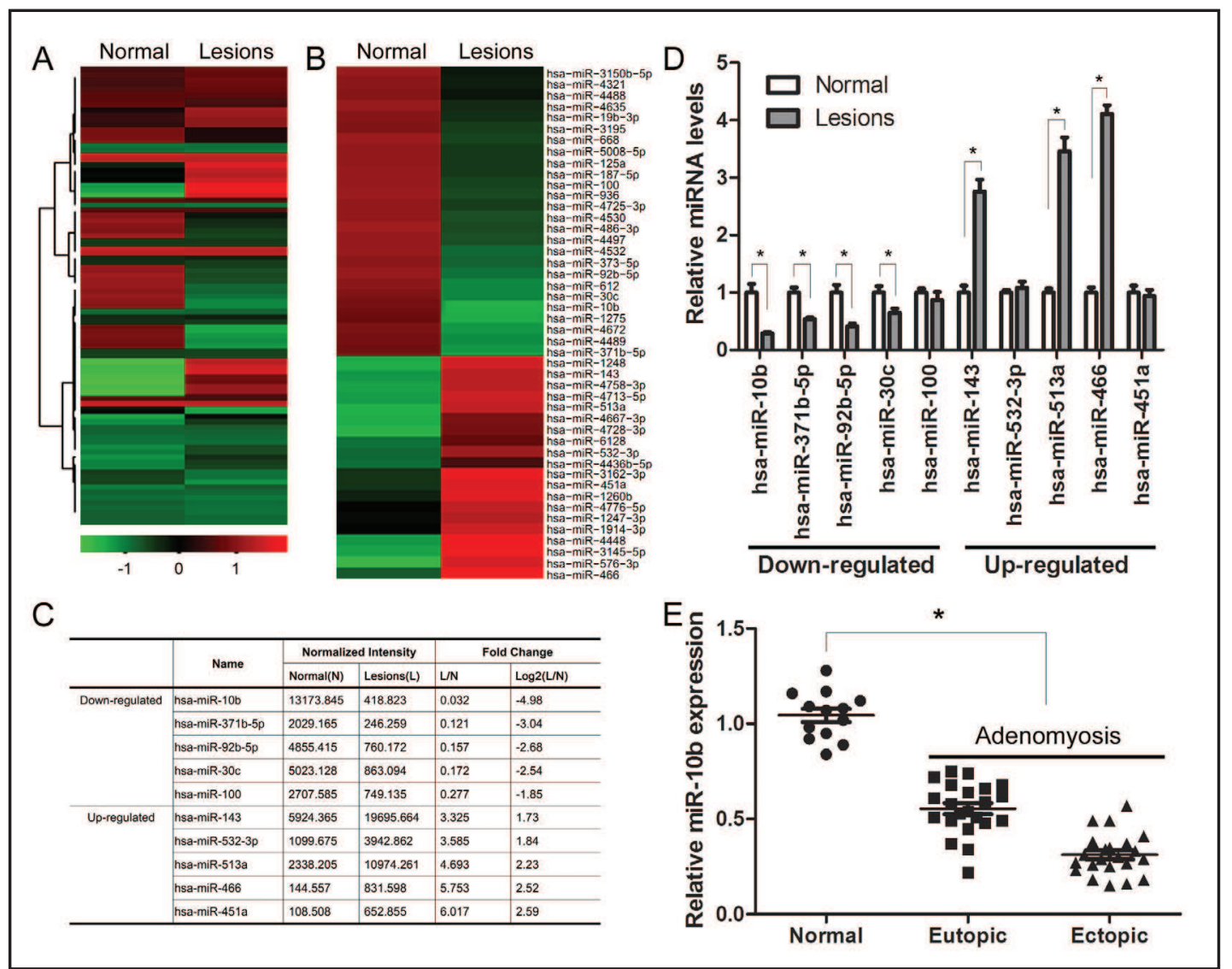

Fig. 1. Identification of deregulated miRNAs in human adenomyosis. (A) Heat map showing the unsupervised filtered clustering of 156 differentially expressed microRNAs between human normal endometrium (Normal) and ectopic endometrial lesions of adenomyosis (Lesions). (B) Heat map showing the clustering of 46 significantly deregulated miRNAs. (C) The normalized absolute and relative signal intensity of 10 most significantly deregulated miRNAs. The relative signal intensity is presented as the ratio and log- 2 transformed ratio of Lesions to Normal. (D) Expression of the 10 most significantly deregulated miRNAs in Normal and Lesions by qRT-PCR. Data were normalized to RNU6B. ${ }^{*} \mathrm{p}<0.05$. (E) MiR-10b expression in normal endometrium $(n=13)$ and paired eutopic and ectopic endometrial tissues of adenomyosis $(n=22$, respectively) by qRT-PCR. Data were normalized to RNU6B. *p<0.05.

\section{Statistical analysis}

Data are interpreted using the GraphPad Prism 5 software (GraphPad Software, Inc, San Diego, CA). All results are presented as the mean \pm SD (standard deviation). To determine statistical differences between two groups Student's $t$-test was used. ANOVA (one-way analysis of variance or repeated measures) was used with the post hoc Bonferroni's test for the comparison of more than two groups. Differences with a $\mathrm{p}$ value less than 0.05 were considered statistically significant.

\section{Results}

MiR-10b expression is downregulated in human adenomyosis

To identify miRNAs deregulated in human adenomysis, we analyzed the expression of 1387 miRNAs in human normal endometrium and ectopic endometrial lesions of adenomyosis using a microarray screen assay. Of the 156 miRNAs that showed differential expression (Fig. 1A), 46 miRNAs were found to be significantly deregulated in ectopic endometrial lesions of adenomyosis versus normal endometrium $(\mathrm{p}<0.05)$ (Fig. 1B). 


\section{Cellular Physiology Cell Physiol Biochem 2015;35:2169-2180 \begin{tabular}{l|l} 
DOI: 10.1159/000374022 & $\begin{array}{l}\text { O 2015 S. Karger AG, Basel } \\
\text { www.karger.com/cpb }\end{array}$ \\
\cline { 2 - 3 }
\end{tabular} \\ Guo et al.: MiR-10b Iinhibits Cell Iinvasiveness by Targeting ZEB1 and PIK3CA in Adenomyosis}
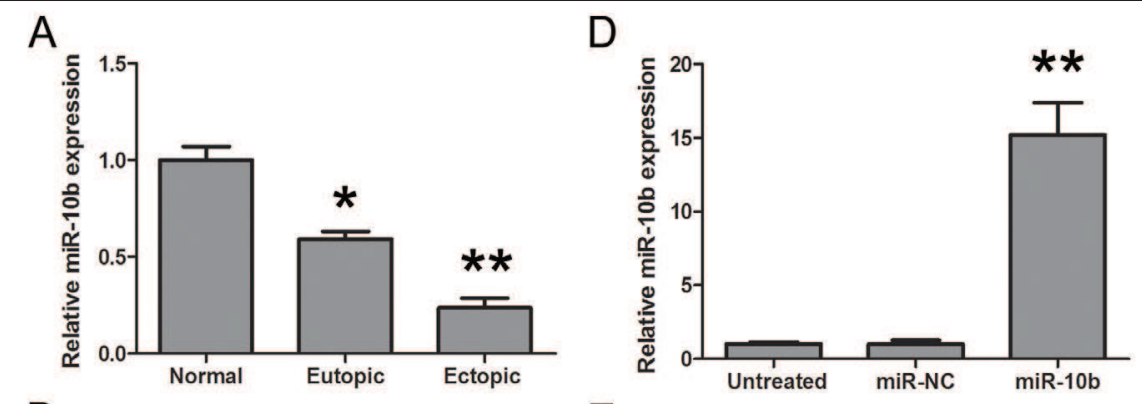

B

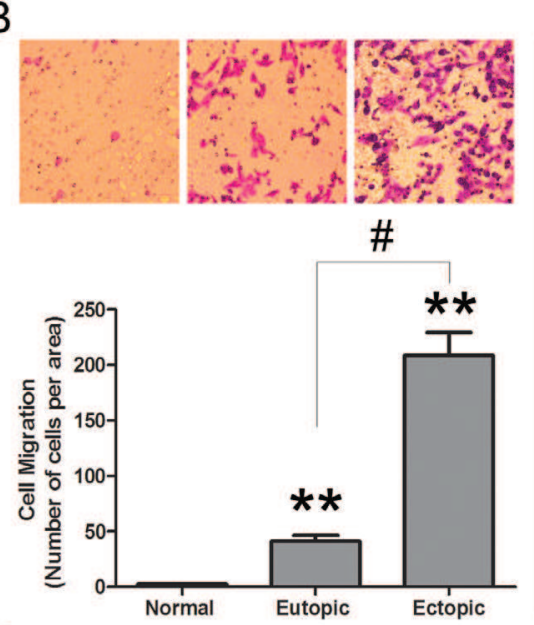

E
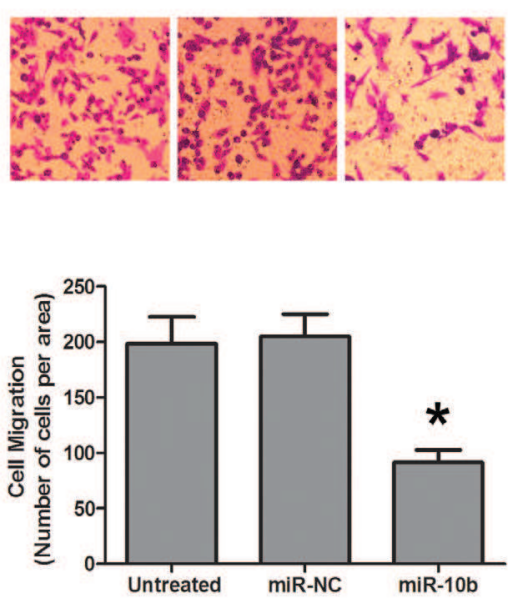

C

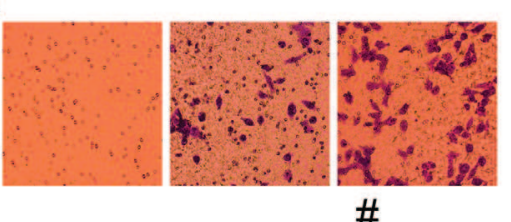

$\mathrm{F}$
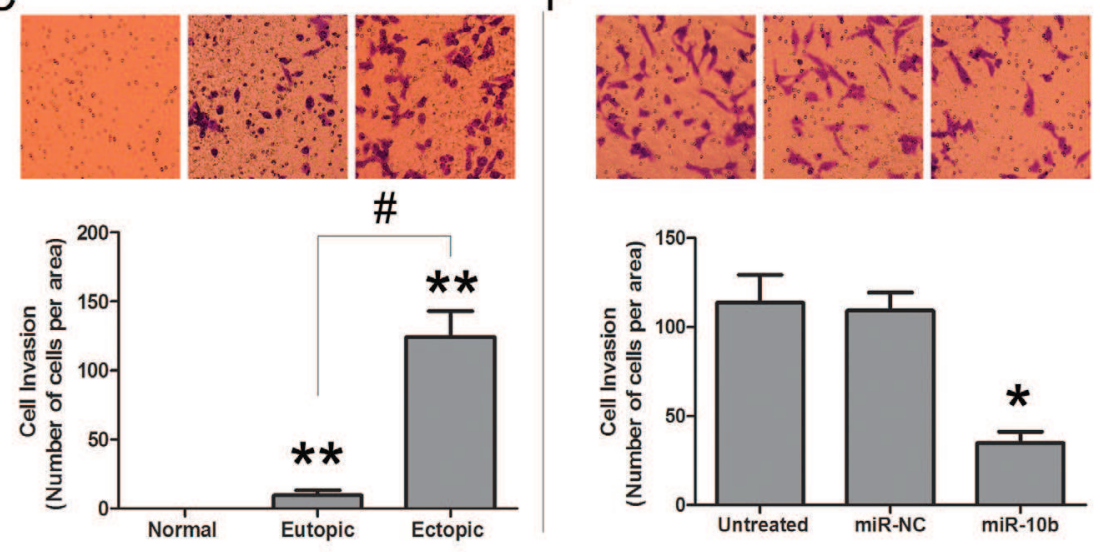

Fig. 2. MiR-10b inhibits adenomyotic epithelial cell migration and invasion. (A-C) Endometrial epithelial cells were isolated from human normal endometrium and paired eutopic and ectopic endometrial tissues of adenomyosis. (A) MiR-10b expression determined by qRT-PCR. Data were normalized to RNU6B. (B-C) Cell migration (B) and cell invasion (C) determined by Transwell assays. Cells that moved through the member and adhered to the lower surface of the membrane were stained with crystal violet and imaged and counted using a microscope. ${ }^{*} \mathrm{p}<0.05,{ }^{* *} \mathrm{p}<0.01$ versus normal. ${ }^{*} \mathrm{p}<0.05$. (D-F) Endometrial epithelial cells isolated from ectopic endometrial tissues of adenomyosis were transiently transfected with miR-10b (50 nM) or miR-NC (50 nM). Untreated cells were included as control. (D) MiR-10b expression determined by qRT-PCR. Data were normalized to RNU6B. (E-F) Cell migration (E) and cell invasion (F) determined by Transwell assays. ${ }^{*} \mathrm{p}<0.05,{ }^{* *} \mathrm{p}<0.01$ versus untreated.

In particular, miR-10b, miR-371b-5p, miR-92b-5p, miR-30c, and miR-100 were most significantly downregulated whilst miR-143, miR-532-3p, miR-513a, miR-466, and miR451a were most significantly upregulated (Fig. 1C). The significant differential expression of 


\section{Cellular Physiology Cell Physiol Biochem 2015;35:2169-2180 \begin{tabular}{ll|l} 
and Biochemistry $10.1159 / 000374022$ & Published online: April 07, 2015 & $\begin{array}{l}\text { ( 2015 S. Karger AG, Basel } \\
\text { www.karger.com/cpb }\end{array}$ \\
\cline { 2 - 3 }
\end{tabular} \\ Guo et al.: MiR-10b Iinhibits Cell linvasiveness by Targeting ZEB1 and PIK3CA in Adenomyosis}

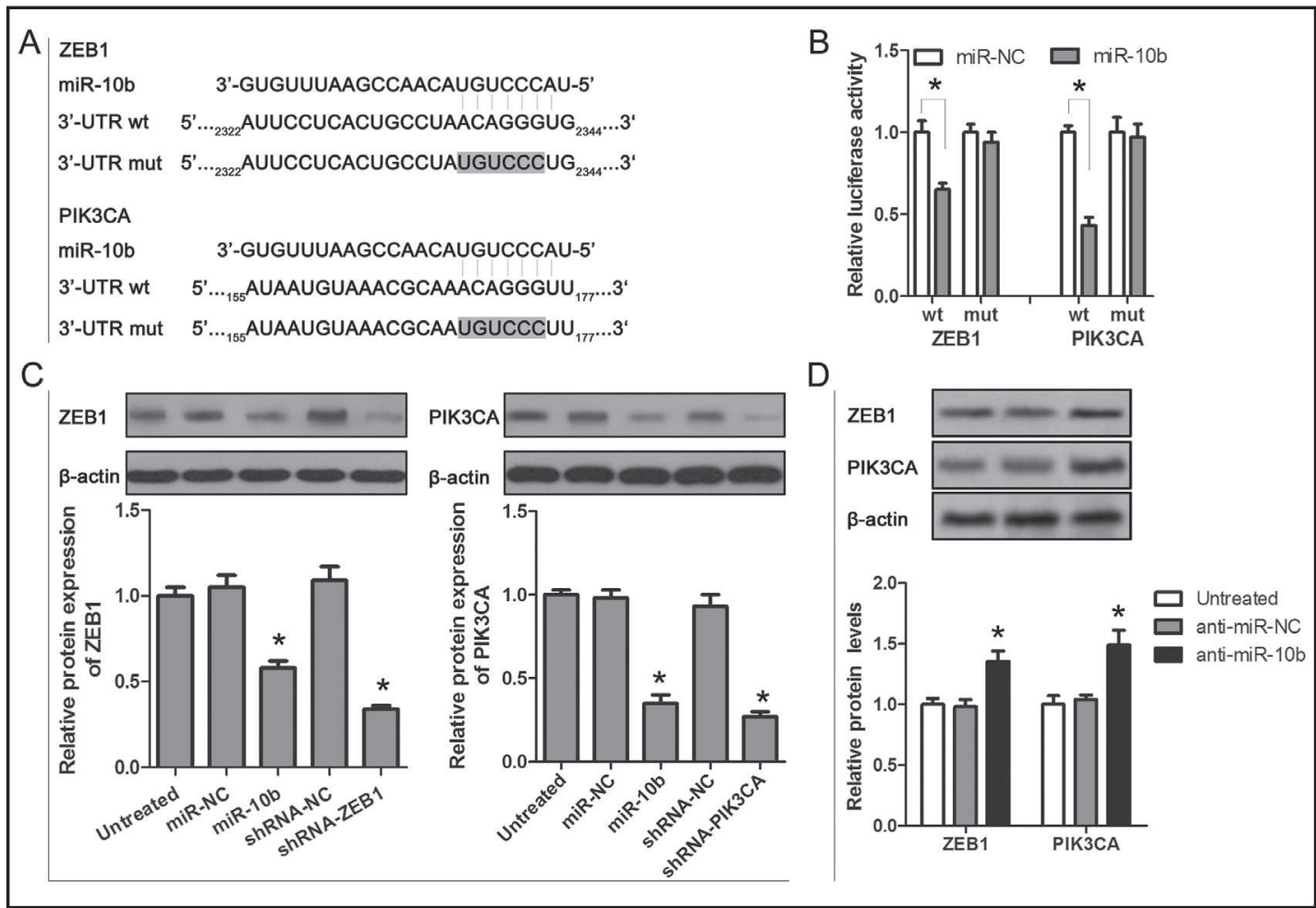

Fig. 3. MiR-10b negatively regulates ZEB1 and PIK3CA expression by directly targeting their 3'-UTRs. (A) Putative binding sites for miR-10b in the 3'-UTRs of ZEB1 and PIK3CA, respectively, predicted by in silico analyses and their respective mutant counterparts. (B) Luciferase activity in HEK293T cells cotransfected with miR-10b or miR-NC and wild-type (wt) or mutant (mut) 3'-UTR of ZEB1 or PIK3CA. Luciferase activity was detected 48 hours after transfection and normalized to Rellina. Luciferase activity in cells transfected with miR-NC was set to $1 .{ }^{*} \mathrm{p}<0.05$. (C-D) Endometrial epithelial cells from ectopic endometrial tissues of adenomyosis were transfected as indicated for $48 \mathrm{~h}$. The protein expression of ZEB1 and PIK3CA was determined by Western blot analysis and normalized to $\beta$-actin. Protein expression in untreated cells was set to 1. ${ }^{*} \mathrm{p}<0.05$ versus untreated.

these miRNAs except miR-100, miR-532-3p, and miR-451a was confirmed by qRT-PCR (Fig. 1D). Importantly, both the microarray screen and the qRT-PCR assay identified miR-10b as the most significantly downregulated miRNA in ectopic endometrial lesions of adenomyosis (Fig. 1C and 1D). Further qRT-PCR analysis showed that, compared with that in human normal endometrium, miR-10b expression progressively declined in paired human eutopic and ectopic endometrium of adenomyosis, although the expression difference between the eutopic and ectopic endometrium did not reach statistical significance (Fig. 1E).

\section{MiR-10b inhibits adenomyotic epithelial cell migration and invasion}

Previousstudieshavereported thatmiR-1bisdownregulatedinhumanendometriosis[13]. Additionally, miR-10b functions to curb the invasiveness of human endometriotic epithelial cells[14]. Having found that miR-10b is also downregulated in human adenomyotic lesions, we proceeded to test the effects of miR-10b on the migration and invasion of adenomyotic epithelial cells. Our qRT-PCR results showed that miR-10b was expressed in endometrial epithelial cells isolated from normal endometrium with a progressive decline in expression in cells isolated from paired eutopic and ectopic endometrium of adenomyosis (Fig. 2A), and the rate of cell migration (Fig. 2B) and invasion (Fig. 2C) was inversely correlated with the level of miR-10b expression. Furthermore, in endometrial epithelial cells isolated from ectopic endometrium of adenomyosis, miR-10b overexpression significantly diminished the rate of cell migration and invasion (Fig. 2D-2F). Taken together, these data suggest that 


\section{Cellular Physiology Cell Physiol Biochem 2015;35:2169-2180 \begin{tabular}{l|l} 
and Biochemistry.1159/000374022 & $\begin{array}{l}\text { D 2015 S. Karger AG, Basel } \\
\text { www.karger.com/cpb }\end{array}$ \\
\cline { 2 - 3 }
\end{tabular} \\ Guo et al.: MiR-10b Iinhibits Cell Iinvasiveness by Targeting ZEB1 and PIK3CA in Adenomyosis}

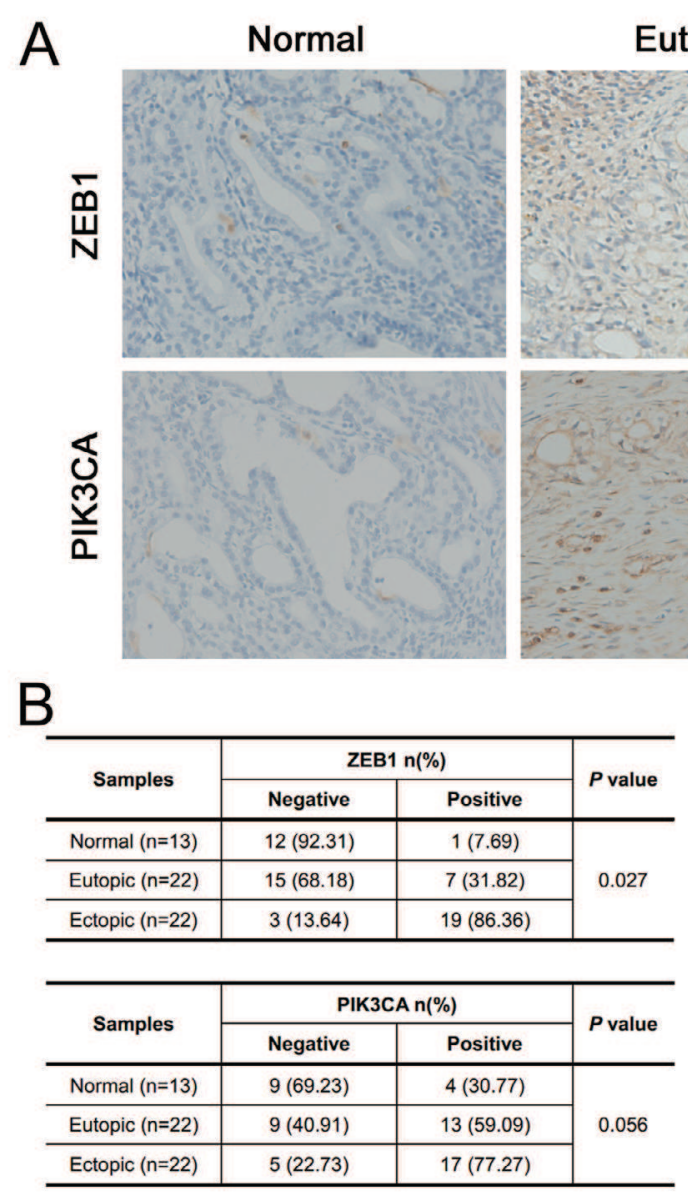

Eutopic
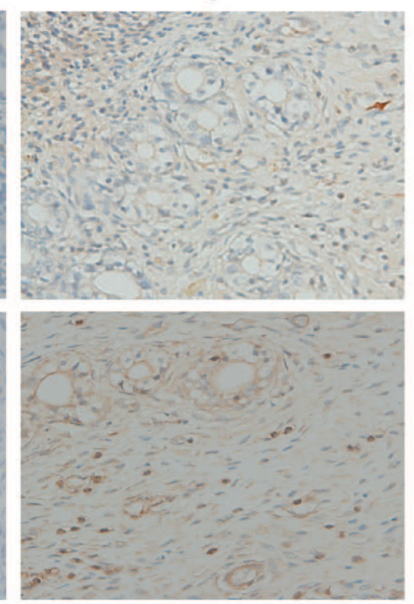

C

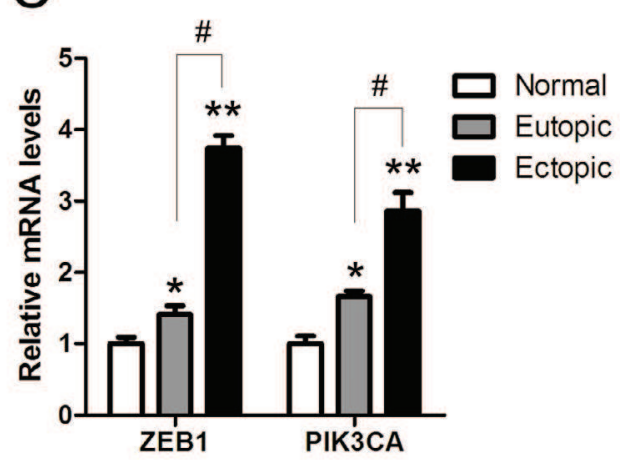

Fig. 4. ZEB1 and PIK3CA expression is upregulated in human adenomyosis. (A) Images of normal endometrium and paired eutopic and ectopic endometrial tissues of adenomyosis subjected to immunohistochemical analysis. (B) Semi-quantitative assessment of ZEB1 and PIK3CA protein expression using immunostaining scores. (C) ZEB1 and PIK3CA mRNA expression determined by qRT-PCR. Data were normalized to GAPDH. ${ }^{*} \mathrm{p}<0.05,{ }^{* *} \mathrm{p}<0.01$ versus normal. ${ }^{*} \mathrm{p}<0.05$.

miR-10b represses the invasiveness of adenomyotic epithelial cells, potentially playing an inhibitory role in the development of adenomyosis.

MiR-10b downregulates ZEB1 and PIK3CA expression by directly targeting their 3'-UTRs

To explore the mechanisms underlying miR-10b-inudced inhibition of the migration and invasion of adenomyotic epithelial cells, we used computational algorithms to identify potential miR-10b target genes. Our in silico analyses using three target prediction softwares (TargetScan, DIANA-microT and microRNA.org) identified putative binding sites for miR$10 \mathrm{~b}$ in the 3'-UTRs of ZEB1 and PIK3CA. To test whether ZEB1 and PIK3CA are direct targets of miR-10b, we prepared luciferase reporter systems using the 3'-UTRs of human ZEB1 and PIK3CA, respectively, containing the putative miR-10b binding site (Fig. 3A). We also created luciferase expression systems using mutant 3'-UTRs in which several nucleotides at the putative binding site were mutated to disrupt miR-10b binding (Fig. 3A). Co-transfection of the luciferase reporter system containing the wild type 3'-UTR of ZEB1 or PIK3CA with miR-10b in HEK293T cells resulted in significant loss of luciferase reporter expression compared with miR-NC ( $\mathrm{p}<0.05$, Fig. 3B). However, luciferase expression was not affected by co-transfection with miR-10b when the wild type 3'-UTR was replaced with mutant 3'-UTR 


\section{Cellular Physiology Cell Physiol Biochem 2015;35:2169-2180 \begin{tabular}{l|l} 
DOI: 10.1159/000374022 & $\begin{array}{l}\text { O 2015 S. Karger AG, Basel } \\
\text { www.karger.com/cpb }\end{array}$ \\
\hline
\end{tabular} \\ Guo et al:: MiR-10b Iinhibits Cell Iinvasiveness by Targeting ZEB1 and PIK3CA in Adenomyosis}
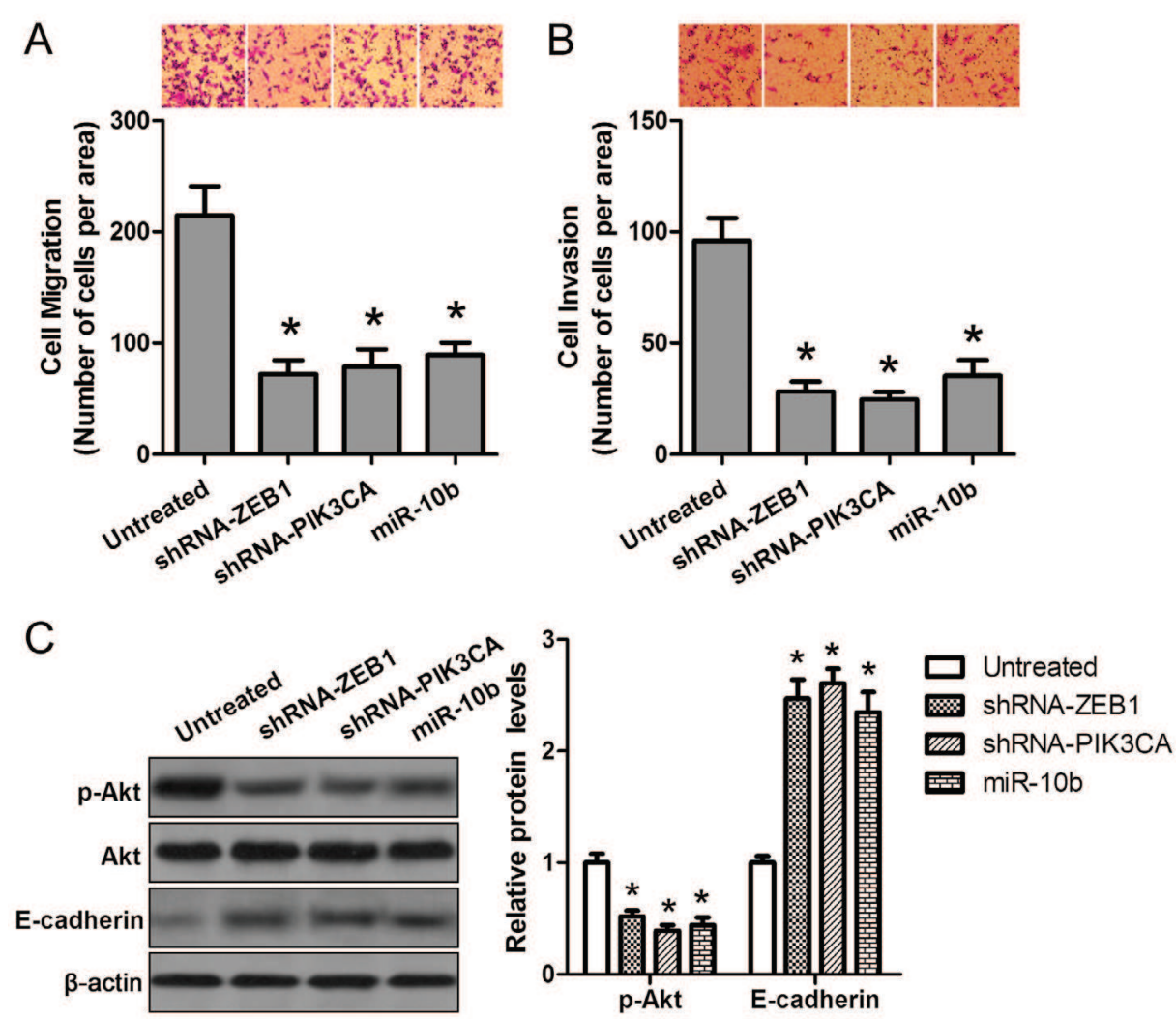

Fig. 5. MiR-10b upregulates E-cadherin expression and inhibits Akt phosphorylation in adenomyotic epithelial cells. Endometrial epithelial cells isolated from ectopic endometrial tissues of adenomyosis were transfected with shRNA-ZEB1, shRNA-PIK3CA, or miR-10b for 48 h. (A-B) Cell migration (A) and cell invasion (B) by Transwell assays. ${ }^{*} \mathrm{p}<0.05$ versus untreated. (C) Protein levels of $\mathrm{p}$-Akt, Akt, and E-cadherin determined by Western blot analysis and normalized to $\beta$-actin. Protein expression in untreated cells was set to $1 .{ }^{*} \mathrm{p}<0.05$ versus untreated.

in the luciferase reporter system (Fig. 3B). Further, in endometrial epithelial cells isolated from ectopic endometrial tissues of adenomyosis, miR-10b overexpression significantly suppressed protein expression of ZEB1 and PIK3CA, similar to that achieved with shRNAmediated gene knockdown (Fig. 3C). Additionally, miR-10b silencing by anti-miR-10b transfection significantly increased protein expression of ZEB1 and PIK3CA in these cells (Fig. 3D). Taken together, these results indicate that miR-10b downregulates ZEB1 and PIK3CA expression by directly targeting their 3'-UTRs.

\section{ZEB1 and PIK3CA expression is upregulated in human adenomyosis}

To explore the potential role of ZEB1 and PIK3CA in human adenomyosis, we analyzed their protein expression in human normal endometrium and paired eutopic and ectopic endometrial tissues of adenomyosis by immunohistochemical analysis. Visual examination of stained tissues revealed progressively increased protein expression of both ZEB1 and PIK3CA in paired human eutopic and ectopic endometrium of adenomyosis compared with that in normal endometrium (Fig. 4A). These results were confirmed by semi-quantitative assessment of protein expression using immunostaining scores (Fig. 4B). qRT-PCR analysis revealed similar progressive increases in mRNA expression of ZEB1 and PIK3CA in these tissues (Fig. 4C). Thus, ZEB1 and PIK3CA expression was upregulated in human adenomyosis and was inversely correlated with miR-10b expression, suggesting that they potentially play a role in the development of human adenomyosis. 


\section{Cellular Physiology Cell Physiol Biochem 2015;35:2169-2180 \\ \begin{tabular}{l|l}
\hline DOI: 10.1159/000374022 & $\begin{array}{l}\text { C 2015 S. Karger AG, Basel } \\
\text { www.karger.com/cpb }\end{array}$ \\
\hline
\end{tabular} \\ Guo et al.: MiR-10b Iinhibits Cell linvasiveness by Targeting ZEB1 and PIK3CA in Adenomyosis}

MiR-10b upregulates E-cadherin expression and inhibits Akt phosphorylation in adenomyotic epithelial cells

The cell-cell adhesion molecule E-cadherin and the PI3K/Akt pathway are implicated in the development of adenomyosis [4, 17-19]. E-cadherin is negatively regulated by transcription factor ZEB1 whilst the p110 $\alpha$ catalytic subunit of PI3K is encoded by PIK3CA. Our findings that ZEB1 and PIK3CA are direct targets of miR-10b suggest that E-cadherin and Akt might be involved in the mechanisms underlying miR-10b-induced effects on adenomyotic epithelial cells. Indeed, in endometrial epithelial cells isolated from ectopic endometrial tissues of adenomyosis, miR-10b overexpression-induced inhibition of cell migration and invasion was accompanied by increased E-cadherin expression and decreased Akt phosphorylation (Fig. 5A-5C). ZEB1 and PIK3CA knockdown in these cells produced similar effects on E-cadherin expression and Akt phosphorylation, respectively, and diminished cell migration and invasion (Fig. 5A-5C). Collectively, these data provided evidence that the ZEB1/E-cadherin and PI3K/Akt signaling pathways are involved in miR$10 \mathrm{~b}$-induced inhibition of adenomyotic epithelial cell migration and invasion.

\section{Discussion}

MiRNAs have been implicated in endometriotic lesion development [25], regulating endometriosis-associated processes including inflammation, tissue repair, cell growth and apoptosis, and angiogenesis [26]. In particular, miR-10b is downregulated in human endometriosis [13] and directly targets syndecan-1 to inhibit endometriotic epithelial cell invasiveness via downregulation of metalloproteinase activity and interleukin-6 [14]. However, the role of miR-10b in adenomyosis, a condition closely related to endometriosis, is unknown. In the present study, we found that miR-10b expression was significantly downregulated in human adenomyotic lesions and adenomyotic epithelial cells. Compared with normal endometrial tissues, eutopic and ectopic endometrial tissues of adenomyosis showed progressively declined miR-10b expression and progressively enhanced cell migration and invasion. Additionally, miR-10b overexpression reduced the migratory and invasive capacity of adenomyotic epithelial cells. To explore the mechanisms underlying these effects, we searched for potential targets of miR-10b and demonstrated that miR$10 \mathrm{~b}$ directly targets the 3'-UTRs of ZEB1 and PIK3CA using a luciferase reporter assay. We also showed that in adenomyotic epithelial cells, miR-10b overexpression downregulated ZEB1 and PIK3CA expression, leading to increased E-cadherin expression and reduced Akt phosphorylation. Collectively, these results suggest that miR-10b directly targets ZEB1 and PI3K to curb adenomyotic epithelial cell invasiveness via upregulation of E-cadherin and inhibition of Akt phosphorylation.

Adenomyosis is enigmatic in terms of etiology. Oestrogen-enhanced migratory and invasive properties of endometrial epithelial cells play a crucial role in the development of adenomyosis $[3,4]$. Our results suggest that miR-10b inhibits the development of adenomyosis by curtailing the invasiveness of adenomyotic epithelial cells. To our knowledge, this is the first report on the role of miRNAs in human adenomyosis. The major limitation of our study is the sample size. It only comprised 22 adenomyosis patients and 13 control women. And the study should be followed by larger population-based and multiethnic studies to confirm our findings. Moreover, the function of miR-10b and other miRNAs in adenomyosis needs to be further investigated.

Current treatment for adenomyosis includes anti-inflammatory medications or hormone therapy to control the pain associated with the disease. The only definitive cure for adenomyosis is a hysterectomy. Uterus-sparing operative treatment is feasible but shows only limited efficacy [27]. Our findings suggest that pharmaceutical interventions targeting miR-10b may provide novel therapy for adenomyosis treatment. 


\section{Cellular Physiology Cell Physiol Biochem 2015;35:2169-2180 \begin{tabular}{ll|l} 
and Biochemistry & $\begin{array}{l}\text { DOI: 10.1159/000374022 } \\
\text { Published online: April 07, } 2015\end{array}$ & $\begin{array}{l}\text { ○ 2015 S. Karger AG, Basel } \\
\text { www.karger.com/cpb }\end{array}$ \\
\hline
\end{tabular} Guo et al.: MiR-10b Iinhibits Cell linvasiveness by Targeting ZEB1 and PIK3CA in Adenomyosis}

\section{Acknowledgements}

This study was supported by grants from the Science and Technology Commission of Shanghai Municipality (No. 12401902901) and the National Natural Science Fundation of China (No. 81441097).

\section{Disclosure Statement}

All authors are in agreement with the content of this manuscript. The authors declare no conflict of interest.

\section{References}

1 Arnold LL, Ascher SM, Schruefer JJ, Simon JA: The nonsurgical diagnosis of adenomyosis. Obstet Gynecol 1995;86:461-465.

2 Juang CM, Chou P, Yen MS, Twu NF, Horng HC, Hsu WL: Adenomyosis and risk of preterm delivery. BJOG 2007;114:165-169.

3 Benagiano G, Brosens I: The endometrium in adenomyosis. Womens Health (Lond Engl) 2012;8:301-312.

4 Chen YJ, Li HY, Huang CH, Twu NF, Yen MS, Wang PH, Chou TY, Liu YN, Chao KC, Yang MH: Oestrogeninduced epithelial-mesenchymal transition of endometrial epithelial cells contributes to the development of adenomyosis. J Pathol 2010;222:261-270.

5 Hayes J, Peruzzi PP, Lawler S: Micrornas in cancer: Biomarkers, functions and therapy. Trends Mol Med 2014;20:460-469.

6 Li G, Wu Z, Peng Y, Liu X, Lu J, Wang L, Pan Q He ML, Li XP: Microrna-10b induced by epstein-barr virusencoded latent membrane protein-1 promotes the metastasis of human nasopharyngeal carcinoma cells. Cancer Lett 2010;299:29-36.

7 Liao CG, Kong LM, Zhou P, Yang XL, Huang JG, Zhang HL, Lu N: Mir-10b is overexpressed in hepatocellular carcinoma and promotes cell proliferation, migration and invasion through rhoc, upar and mmps. J Transl Med 2014;12:234.

8 Ma L, Teruya-Feldstein J, Weinberg RA: Tumour invasion and metastasis initiated by microrna-10b in breast cancer. Nature 2007;449:682-688.

9 Sasayama T, Nishihara M, Kondoh T, Hosoda K, Kohmura E: Microrna-10b is overexpressed in malignant glioma and associated with tumor invasive factors, upar and rhoc. Int J Cancer 2009;125:1407-1413.

10 Tian Y, Luo A, Cai Y, Su Q Ding F, Chen H, Liu Z: Microrna-10b promotes migration and invasion through klf4 in human esophageal cancer cell lines. J Biol Chem 2010;285:7986-7994.

11 Hiroki E, Akahira J, Suzuki F, Nagase S, Ito K, Suzuki T, Sasano H, Yaegashi N: Changes in microrna expression levels correlate with clinicopathological features and prognoses in endometrial serous adenocarcinomas. Cancer Sci 2010;101:241-249.

12 Tsukamoto O, Miura K, Mishima H, Abe S, Kaneuchi M, Higashijima A, Miura S, Kinoshita A, Yoshiura K, Masuzaki H: Identification of endometrioid endometrial carcinoma-associated micrornas in tissue and plasma. Gynecol Oncol 2014;132:715-721.

13 Pan Q, Luo X, Toloubeydokhti T, Chegini N: The expression profile of micro-rna in endometrium and endometriosis and the influence of ovarian steroids on their expression. Mol Hum Reprod 2007;13:797806.

14 Schneider C, Kassens N, Greve B, Hassan H, Schuring AN, Starzinski-Powitz A, Kiesel L, Seidler DG, Gotte M: Targeting of syndecan-1 by micro-ribonucleic acid mir-10b modulates invasiveness of endometriotic cells via dysregulation of the proteolytic milieu and interleukin-6 secretion. Fertil Steril 2013;99:871-881 e871.

15 Franco-Chuaire ML, Magda Carolina SC, Chuaire-Noack L: Epithelial-mesenchymal transition (emt): Principles and clinical impact in cancer therapy. Invest Clin 2013;54:186-205.

16 Polyak K, Weinberg RA: Transitions between epithelial and mesenchymal states: Acquisition of malignant and stem cell traits. Nat Rev Cancer 2009;9:265-273. 


\section{Cellular Physiology Cell Physiol Biochem 2015;35:2169-2180 \begin{tabular}{l|l} 
DOI: 10.1159/000374022 & $\begin{array}{l}\text { O } 2015 \mathrm{~S} \text {. Karger AG, Basel } \\
\text { www.karger.com/cpb }\end{array}$ \\
\hline
\end{tabular} \\ Guo et al.: MiR-10b Iinhibits Cell Iinvasiveness by Targeting ZEB1 and PIK3CA in
Adenomyosis}

17 Oh SJ, Shin JH, Kim TH, Lee HS, Yoo JY, Ahn JY, Broaddus RR, Taketo MM, Lydon JP, Leach RE, Lessey BA, Fazleabas AT, Lim JM, Jeong JW: Beta-catenin activation contributes to the pathogenesis of adenomyosis through epithelial-mesenchymal transition. J Pathol 2013;231:210-222.

18 Cakmak H, Guzeloglu-Kayisli O, Kayisli UA, Arici A: Immune-endocrine interactions in endometriosis. Front Biosci (Elite Ed) 2009;1:429-443.

19 Xue J, Zhang H, Liu W, Liu M, Shi M, Wen Z, Li C: Metformin inhibits growth of eutopic stromal cells from adenomyotic endometrium via ampk activation and subsequent inhibition of akt phosphorylation: A possible role in the treatment of adenomyosis. Reproduction 2013;146:397-406.

20 Cikos S, Bukovska A, Koppel J: Relative quantification of mrna: Comparison of methods currently used for real-time pcr data analysis. BMC Mol Biol 2007;8:113.

21 Zhang L, Rees MC, Bicknell R: The isolation and long-term culture of normal human endometrial epithelium and stroma. Expression of mrnas for angiogenic polypeptides basally and on oestrogen and progesterone challenges. J Cell Sci 1995;108 ( Pt 1):323-331.

22 Dong PX, Jia N, Xu ZJ, Liu YT, Li DJ, Feng YJ: Silencing of iqgap1 by shrna inhibits the invasion of ovarian carcinoma ho-8910pm cells in vitro. J Exp Clin Cancer Res 2008;27:77.

23 Su H, Yang JR, Xu T, Huang J, Xu L, Yuan Y, Zhuang SM: Microrna-101, down-regulated in hepatocellular carcinoma, promotes apoptosis and suppresses tumorigenicity. Cancer Res 2009;69:1135-1142.

24 Dong P, Kaneuchi M, Xiong Y, Cao L, Cai M, Liu X, Guo SW, Ju J, Jia N, Konno Y, Watari H, Hosaka M, Sudo S, Sakuragi N: Identification of klf17 as a novel epithelial to mesenchymal transition inducer via direct activation of twist1 in endometrioid endometrial cancer. Carcinogenesis 2014;35:760-768.

25 Dai L, Di W: [role of microrna in the occurrence and development of endometriosis]. Zhonghua Fu Chan Ke Za Zhi 2011;46:304-306.

26 Lin SC, Wang CC, Wu MH, Yang SH, Li YH, Tsai SJ: Hypoxia-induced microrna-20a expression increases erk phosphorylation and angiogenic gene expression in endometriotic stromal cells. J Clin Endocrinol Metab 2012;97:E1515-1523.

27 Grimbizis GF, Mikos T, Tarlatzis B: Uterus-sparing operative treatment for adenomyosis. Fertil Steril 2014;101:472-487. 